\title{
Deep brain stimulation in Parkinson's disease
}

\author{
S. J. Groiss, L. Wojtecki, M. Südmeyer and A. Schnitzler
}

\begin{abstract}
During the last 15 years deep brain stimulation (DBS) has been established as a highly-effective therapy for advanced Parkinson's disease (PD). Patient selection, stereotactic implantation, postoperative stimulator programming and patient care requires a multi-disciplinary team including movement disorders specialists in neurology and functional neurosurgery. To treat medically refractory levodopa-induced motor complications or resistant tremor the preferred target for high-frequency DBS is the subthalamic nucleus (STN). STN-DBS results in significant reduction of dyskinesias and dopaminergic medication, improvement of all cardinal motor symptoms with sustained long-term benefits, and significant improvement of quality of life when compared with best medical treatment. These benefits have to be weighed against potential surgery-related adverse events, device-related complications, and stimulus-induced side effects. The mean disease duration before initiating DBS in PD is currently about 13 years. It is presently investigated whether the optimal timing for implantation may be at an earlier disease-stage to prevent psychosocial decline and to maintain quality of life for a longer period of time.
\end{abstract}

Keywords: deep brain stimulation, DBS, Parkinson's disease, subthalamic nucleus, STN, GPi, VIM

\section{Introduction}

Parkinson's disease (PD) is a disabling chronic neurodegenerative disorder clinically characterized by akinesia, tremor, rigidity, and postural instability, caused mainly by dopaminergic neuron degeneration of the substantia nigra [Hughes et al. 1992]. Levodopa and a number of dopamine agonists are available for a dopamine-replacement therapy resulting in an effective relief of motor symptoms in the early stage of the disease. However, this treatment is eventually hampered by the increasing occurrence of motor complications, such as wearing-off and suddenoff phenomena as well as troublesome hyperkinesias [Goetz et al. 2005]. Prior to the introduction of Levodopa [Birkmayer et al. 1961], surgical lesional procedures - in particular pallidotomies and thalamotomies - were applied as ultima ratio for treatment of refractory symptoms. The result was an improvement of symptoms, but often at the risk of irreversible and severe side effects like dysarthria or hemiparesis. Bilateral surgery dramatically increased complications and was therefore rarely performed.

Deep brain stimulation (DBS) of the motor thalamus, the ventral intermedius nucleus (VIM), was first used in 1986 to treat medically refractory tremor in PD [Benabid et al. 1987]. DBS of various basal ganglia nuclei has since developed into a highly-effective treatment for several movement disorders. In PD, DBS of the internal globus pallidus (GPi) and the subthalamic nucleus (STN) were found to be effective and safe targets.

Compared with surgical lesioning procedures, chronic DBS used with the standard stimulation parameters for PD leads to no, or only minimal, tissue damage [Pilitsis et al. 2008; Kuncel and Grill, 2004; Burbaud et al. 2002; Haberler et al. 2000] and is therefore largely reversible. Furthermore, unlike lesioning, bilateral DBS can be implemented without significantly increasing side effects. It is possible to adjust stimulation parameters postoperatively and in the course of the disease. In different randomized controlled trials DBS showed a better functional outcome with fewer side effects [Esselink et al. 2004; Schuurman et al. 2000] and therefore almost completely replaced lesional surgery in industrialized nations. However, due to economic restrictions in particular countries, lesioning still might be the only option.
Ther Adv Neurol Disord (2009) 2(6) 379-391 DOI: $10.1177 /$ 1756285609339382 (C) The Author(s), 2009 Reprints and permissions: http://www.sagepub.co.uk/ journalsPermissions.nav

Correspondence to: A. Schnitzler Professor in Neurology, Director of the Institute of Clinical Neuroscience and Medical Psychology,

Heinrich-Heine-University Düsseldorf, Germany, Department of Neurology, Center for Movement Disorders and Neuromodulation, Heinrich-Heine-University Düsseldorf, Germany alfons.schnitzlerla uni-duesseldorf.de

S. J. Groiss

L. Wojtecki

M. Südmeyer

Department of Neurology, Center for Movement

Disorders and

Neuromodulation, Heinrich-Heine-University of Düsseldorf, Germany, Institute of Clinical Neuroscience and Medical Psychology, Heinrich-

Heine-University of Düsseldorf, Germany 


\section{Patient selection}

The selection of appropriate patients is of particular importance and individual risk versus benefit ratio has to be carefully assessed. DBS in parkinsonian syndromes is thought to be successful only in idiopathic PD including monogenic parkinsonism [Moro et al. 2008]. With the exception of tremor which often shows a varied response, dopaminergic medication is highly effective for the treatment of all cardinal motor symptoms but leads to long-term motor complications like wearing off and/or disabling dyskinesias. Prevalence of overall levodopa-induced motor fluctuations after a mean of 5 years of treatment reaches up to $50 \%$, increases with the duration of the treatment and is especially high in younger patients [Le Witt, 2008; Ahlskog and Muenter, 2001; Olanow et al. 2001; Rascol et al. 2000]. Symptoms best controlled by DBS can be classified into (a) levodopa-sensitive OFF symptoms; (b) levodopa-induced dyskinesias; and (c) tremor.

Concerning STN-DBS, the principal response to dopaminergic medication has the highest predictive value for a good and persistent motor outcome with stimulation [Pahwa et al. 2006; Kleiner-Fisman et al. 2003; Benabid et al. 2002; Charles et al. 2002; Welter et al. 2002; Krack et al. 1998]. Symptoms that are resistant to dopaminergic medication are typically also resistant to DBS. Patients, therefore, should achieve an improvement of at least $30 \%$ in the preoperative levodopa-test measured by the Unified Parkinson's Disease Rating Scale (UPDRS) motor score. The OFF score should be performed after an interruption of antiparkinsonian medication for at least 12 hours and the ON score in the best clinical state after administration of a single suprathreshold levodopa-dose, which is typically 1.5 times the effective levodopa morning-dose equivalent [Langston et al. 1992]. An improvement of more than $50 \%$ would be desirable as a direct correlation of preoperative levodopa responsiveness and outcome after STN-DBS has been shown [Kleiner-Fisman et al. 2003; Welter et al. 2002]. Lower preoperative levodopa-response has been associated with a decline in postoperative cognitive screening tests [Smeding et al. 2006]. OFF phases should cover more than $25 \%$ of the awake time and should have a minimum severity of 30/108 points on the UPDRS motor score [Hilker et al. 2009]. Peak-dose-hyperkinesias and biphasic dyskinesias as well as OFF-dystonia respond well to DBS [Krack et al. 1999]. Severe disabling tremor is the only symptom which, up to 80-90\%, shows an excellent response to DBS, even when resistant to levodopa. Tremor is therefore a good target symptom for STN-DBS [Krack et al. 1997].

Freezing of gait, postural instability or dysarthrophonia persisting during best medical-ON state revealed no significant improvement after STNDBS [Charles et al. 2002; Welter et al. 2002]. Atypical parkinsonian syndromes, e.g. multiple system atrophy or progressive supranuclear palsy, show at best slight and transient improvement and should not be treated with DBS [Lang et al. 2006]. Autonomic dysfunctions in an early stage suggest an atypical parkinsonism and, if present, must be critically reviewed. Although there is evidence that bladder function in PD can be slightly improved by DBS [Herzog et al. 2006], it is currently no main target for the indication of DBS.

Another important parameter for prediction of outcome is age. Biological age shows an inverse correlation with improvement of motor function and a positive correlation with perioperative complications even in experienced and specialized centers [Weaver et al. 2009; Voges et al. 2007; Charles et al. 2002, Welter et al. 2002].

Finally, prior to implanting DBS electrodes for chronic stimulation, evaluation of cognitive function and neuropsychiatric symptoms is of crucial importance. Manifest dementia and/or psychiatric disorders like psychosis or depression persisting during $\mathrm{ON}$, or personality disorders are contraindications for DBS.

Inclusion and exclusion criteria are as follows:

Inclusion

(1) clinically idiopathic PD

(2) significant improvement with regard to dopaminergic medication ( $>30 \%$ )

(3) refractory motor fluctuations or tremor

(4) only minor symptoms during ON-state

Exclusion (relative)

(1) biological age over 75 years

(2) severe/malignant comorbidity with considerably reduced life-expectancy

(3) chronic immunosuppression 
(4) distinct brain atrophy

(5) severe psychiatric disorder (cognitve deficits/ dementia, frontal-dysexecutive syndrome, manifest psychosis, depression, substance abuse, personality disorder)

\section{Target points}

Currently STN is the main target nucleus for DBS in PD. All cardinal symptoms that principally respond well to levodopa, including akinesia, rigidity, tremor, and postural instability can be effectively treated by STN-DBS. The best outcome might be achieved by stimulation of the dorsolateral motor part of the STN [Herzog et al. 2004; Voges et al. 2002], but there is evidence that stimulation of the zona incerta also results in good improvement [Plaha et al. 2006]. STN-DBS should usually be performed bilaterally to alleviate motor symptoms on both sides and allow for optimal reduction of medication [Kumar et al. 1999].

DBS of GPi shows an immediate and significant reduction of levodopa-induced disabling dyskinesias. The effect on OFF-symptoms might be less pronounced [The DBS for PD study group, 2001]. However, the excellent reduction of dyskinesias allows a further increase of dopaminergic medication and consecutive improvement of motor symptoms. In previous studies comparing STN-DBS with GPi-DBS there were no significant differences in motor outcome between these targets [Okun et al. 2009; Weaver et al. 2005; The DBS for PD study group 2001; Burchiel et al. 1999], but there are several reasons which favor STN for the majority of PD-patients. First, GPi-DBS does not allow for a reduction of medication [Volkmann et al. 2004]. Second, with regard to OFF-symptoms, a weakening of improvement after GPi-DBS over the years has been described [Volkmann et al. 2004]. Also, GPi-DBS commonly requires higher settings which results in shorter battery life-spans [Volkmann et al. 2001]. A large randomized, prospective multicenter study including 255 patients and directly comparing STN- and GPiDBS with best medical treatment is currently being conducted [Weaver et al. 2009]. For the first 6-month period of the trial the two target groups were pooled into one DBS group which does not allow comparison of the efficacy between the two targets. However the second phase of the study will directly compare the improvement of STN-DBS and GPi-DBS and will shed further light on this issue.

In a majority of PD-patients VIM-DBS leads to an immediate and almost complete suppression of tremor [Benabid et al. 1996], but has no effect on akinesia and rigidity. Therefore, VIM-DBS is only rarely performed in PD but may sometimes still be an option in older patients with unilateral tremor-dominant PD.

The pedunculopontine nucleus has recently aroused interest as a new target for DBS in PD [Stefani et al. 2007]. However, the benefit was limited within the small patient group and until now this procedure remains experimental.

\section{Perioperative management}

Pre- and intraoperative procedure

Preparation begins several days before surgery with the reduction of the dopamine agonist. Levodopa should be withdrawn on the eve of the operation. During surgery awake patients should be kept in an appropriate OFF-condition as an experienced movement disorders specialist has to evaluate the effect of DBS by test stimulation intraoperatively.

Localization of the target point is based on stereotactic coordinates [Schaltenbrand and Wahren, 1977, Schaltenbrand and Bailey, 1959; Talairach et al. 1957] and adapted individually using image fusion of cranial magnetic resonance imaging (cMRI) and cranial computed tomography (CCT) [Schuurmann et al. 1999; Starr et al. 1999]. Direct visualization of the target nucleus by high-resolution MRI with a voxel size $<1.5 \mathrm{~mm}^{3}$ and high contrast requires axial/coronar T2 and/or inversion recovery sequences and might be superior to indirect target point calculation [Andrade-Souza et al. 2005; Vayssiere et al. 2002].

For further verification of the electrode position, intraoperative analyses using different neurophysiological techniques have to be performed. Test stimulation in the target area to identify the site of the best therapeutic effect is usually performed by an experienced movement-disorders specialist. Furthermore, mapping the side effects - e.g. oculomotor dysfunction, tetanic contractions, paresthesia, nausea, etc. which may occur during co-stimulation of neighbouring nuclei or fibers helps to identify the borders of the target nucleus. 
The correct positioning of the electrodes can be improved by the use of multitrajectory microelectrode-recording (MER) to register the characteristic activity patterns of the cells in the different nuclei [Hamani et al. 2005; Lozano et al. 1998]. On the other hand, there is a debate whether MER may increase the risk of cerebral hemorrhages [Hariz, 2002; Palur et al. 2002; The DBS for PD study group, 2001].

The tip of the final DBS-electrode used for chronic stimulation has four contacts and each of them can be activated separately for stimulation. This allows for a minor modification of the stimulated area, even if the electrode is already implanted. Intra- and postoperative controls of electrode position using stereotactic x-ray, CCT, or cMRI for correct targeting are indispensable. After implantation of the electrodes they are connected to the pulse generator which is implanted subcutaneously at an infraclavicular or abdominal site.

\section{Postoperative care and stimulator settings}

The postoperative adjustment of stimulator settings in STN-DBS remains time-consuming. Usually, stimulation parameters and medication have to be adapted reiteratively. Post-surgery an immediate and significant improvement of symptoms may occur without activating the stimulator. This clinical improvement is attributed to a microlesioning effect and disappears in the course of time. It can last up to several months but in most cases diminishes in the first days and weeks. Once the microlesioning effect has faded, all four electrode contacts should be tested carefully and the contact with the best effect and highest-threshold for side effects be selected for chronic stimulation. In the following days and weeks, stimulation amplitude will be increased successively, paralleled by a gradual decrease of levodopa dosage, until a good mobility is achieved with no significant dyskinesias [Volkmann et al. 2006, 2000]. Typical stimulation parameters for chronic DBS are monopolar stimulation, voltage $2.5-3.5 \mathrm{~V}$, impulse duration $60-90 \mu \mathrm{s}$ and frequency $130-180 \mathrm{~Hz}$. Several issues have to be taken into account when adapting the stimulator settings. Depending on the side effects occurring during chronic stimulation, it may become necessary to change to bipolar stimulation or activate a different contact. Stimulation-induced dyskinesias may occur with a delay after parameters have been increased, that is, major changes should be avoided in the late evening or before the weekend. Occasionally, it is difficult to distinguish OFF-associated dystonia and stimulation-induced dystonia. In these cases, the stimulation effect in the OFFcondition has to be re-evaluated. Furthermore acute effects on mood and subjective well-being following STN-DBS are well-known phenomena [Funkiewitz et al. 2003; Schneider et al. 2003]. Overly rapid changes of stimulation parameters may even directly induce affective phenomena, e.g. mirthful laughter or pathological crying [Wojtecki et al. 2007; Krack et al. 2001]. Should the dopaminergic medication be reduced too rapidly, disabling mood disturbances may occur which may require medical intervention [Okun et al. 2003].

Because of the complexity of STN-DBS the patient's outcome improves if a movement disorders and DBS specialist programs the device, and if implantation and postoperative patient care is performed in a specialized center [Moro et al. 2006].

Programming the devices for GPi-DBS and VIM-DBS is less complex as the medication does not have to be adapted. Once the active contact with the best efficacy/side effect profile has been selected, it is usually possible to increase the parameters faster than with STN-DBS. VIMDBS stimulation parameters are similar to those used in STN-DBS, while GPi-DBS often requires higher amplitudes and/or impulse duration [Deuschl et al. 2002; Volkmann et al. 2000].

If standard stimulator settings are used, the capacity of the battery is exhausted after 4-6 years and a surgical replacement of the battery becomes necessary. Recently, a new stimulation device has been introduced which allows wireless recharging of the battery without surgery.

\section{Clinical outcome}

Several studies have shown significant improvement of motor function after bilateral STN-DBS or GPi-DBS in advanced PD [Krack et al. 2003; The DBS for PD study group, 2001; Limousin et al. 1998; Volkmann et al. 1998,]. STN-DBS results in a mean reduction of OFF-symptoms of $60 \%$ and in most cases the dopaminergic medication can be reduced significantly which leads to a reduction of disabling dyskinesias by about $60 \%$ [Krack et al. 2003; The DBS for PD study group, 2001]. DBS of the GPi shows an immediate reduction of levodopa-induced 
disabling dyskinesias of about $80 \%$ [Volkmann et al. 2004]. UPDRS motor-score was improved from $37 \%$ (GPi) to $49 \%$ (STN) after surgery and the percentage of time with good mobility and without disabling dyskinesias was more than doubled [The DBS for PD study group, 2001]. These results are consistent with findings in other studies and were finally confirmed in a large prospective, randomized, multicenter study showing a $41 \%$ improvement of motor function 6 months postoperatively [Deuschl et al. 2006]. This study was also the first to show a significant advantage of DBS compared with best medical treatment and a significant improvement in quality of life. During a 6-month follow-up period a generic quality of life scale (SF-36) showed an improvement of $22 \%$ and a disease-related quality of life score (PDQ-39) revealed an overall improvement of $25 \%$ in the DBS group. Regarding PDQ-39 subscores, improvements of $24-38 \%$ were recorded for mobility, activities of daily living (ADL), emotional well-being, stigma, and bodily discomfort [Deuschl et al. 2006]. Similar results were found in a recent large controlled trial where patients were randomized into STNDBS or GPi-DBS or best medical treatment [Weaver et al. 2009]. Although older patients were included in the study $(25 \%$ aged $70+$ years) an improvement of the OFF-time UPDRS motor score by $29 \%$ was observed in the DBS group. Overall the PDQ-39 score improved by $17 \%$ [Weaver et al. 2009].

Long-term observations after STN-DBS showed an improvement in UPDRS motor scores of $66 \%$ at 1 year and $54 \%$ at 5 years after implantation [Krack et al. 2003]. This slight decrease in motor improvement after 5 years likely reflects disease progression. While reduction of levodopa-induced dyskinesias after GPi-DBS seems to remain significantly reduced, OFF-period motor symptoms and motor fluctuations gradually decline [Volkmann et al. 2004], with improvements in ADL scores lost after the first year. Replacement of GPi electrodes into the STN can restore the initial benefit and result in a significant reduction of dopaminergic medication [Volkmann et al. 2004]. Another multicenter trial found sustained improvement in motor function over a period of 4 years after STN-DBS as well as GPi-DBS [Rodriguez-Oroz et al. 2005].

The long-term follow-up of VIM-DBS revealed effective control of tremor 6 years postoperatively while axial symptoms worsened. The initial improvement in ADL-scores at the 1 year follow-up disappeared after 6 years [Hariz et al. 2008]. Table 1 gives an overview of studies investigating the clinical outcome of DBS.

It remains unclear currently whether DBS exerts neuroprotective effects. Several studies have shown a lasting effect, of at least 4-5 years in duration, with marked improvement of motor function [Visser-Vandewalle et al. 2005; Kleiner-Fisman et al. 2003; Krack et al. 2003], but they have been unable to demonstrate any influence of DBS on progression and the natural course of the disease [Krack et al. 2003]. In a imaging study using positron emission tomography (PET), a continuous decline of dopaminergic function under effective STN-DBS was shown which was comparable with the natural progression [Hilker et al. 2005]. However, recent animal studies show a saving of dopaminergic cells after STN-DBS which might lead to a slowing of disease progression [Wallace et al. 2007; Temel et al. 2006].

\section{Complications and side effects}

In recent years, improvements of cerebral imaging techniques have greatly increased the safety of functional neurosurgery, but surgery-related complications remain a possibility. The most severe complication of DBS surgery is intracerebral hemorrhage (ICH) which is reported to occur in $0.2-5 \%$ (Table 2). The degree of hemorrhages varies from asymptomatic ICH to severe ICH resulting in significant and persistent neurological deficits or death. A large variability in the number of postoperative infections ranging from $1.8-15.2 \%$ of cases is reported [Oh et al. 2002; Limousin et al. 1999]. Infections most commonly occur in the area surrounding the pulse generator [Voges et al. 2007; Lyons et al. 2004; The DBS for PD study group, 2001] (Table 2). Treatment with systemic antibiotics and local surgicallavation usually suffices, but in severe cases the implanted device has to be removed to prevent further spreading of the infection [Voges et al. 2007]. Other hardware complications include lead breakage or malfunction of the pulse generator [Voges et al. 2007; Lyons et al. 2004]. Table 2 summarizes the complications related to electrode implantation and hardware reported in trials including more than 100 patients.

Decrease of cognitive function was initially assumed to occur especially in older patients or those with preoperative cognitive deficits 
Table 1. Clinical outcome after subthalamic nucleus/internal globus pallidus deep brain stimulation.

\begin{tabular}{|c|c|c|c|c|c|c|c|}
\hline & $\begin{array}{l}\text { Number of } \\
\text { patients }\end{array}$ & $\begin{array}{l}\text { Follow-up } \\
\text { lyears) }\end{array}$ & $\begin{array}{l}\text { Improvement } \\
\text { UPDRS* } \\
\text { II }(\%)\end{array}$ & $\begin{array}{l}\text { Improvement } \\
\text { OFF-UPDRS* } \\
\text { III (\%) }\end{array}$ & $\begin{array}{l}\text { Decrease } \\
\text { OFF-time } \\
(\%)\end{array}$ & $\begin{array}{l}\text { Increase } \\
\text { ON-time } \\
\text { w/o dyskinesia } \\
(\%)\end{array}$ & $\begin{array}{l}\text { Improvement } \\
\text { PDQ-39\$ }(\%)\end{array}$ \\
\hline \multicolumn{8}{|l|}{ Original studies: } \\
\hline Krack et al. 1997 & 15 & 1 & & 71 & & & \\
\hline Kumar et al. 1998 & 7 & 1 & 30 & 58 & 80 & 200 & \\
\hline Limousin et al. 1998 & 20 & 1 & 58 & 60 & 72.7 & & \\
\hline DBSPDSG 2001 & 96 & 0.5 & & 51 & 61 & $270-229$ & \\
\hline Volkmann et al. 2001 & 16 & 1 & & 67 & & & \\
\hline Pahwa et al. 2003 & 19 & 2.3 & 27 & 28 & 61 & & \\
\hline Krack et al. 2003 & 49 & 5 & $66-49$ & $66-54$ & & & \\
\hline $\begin{array}{l}\text { Rodriguez-Oroz } \\
\text { et al. } 2005\end{array}$ & 49 & 3 & $43-28$ & $50-39$ & $56-43$ & $260-265$ & \\
\hline Fraix et al. 2006 & 95 & 1 & 48 & 57 & & 192 & 28 \\
\hline Deuschl et al. 2006 & 156 & 0.5 & 39 & 41 & 64 & 237 & 24 \\
\hline Weaver et al. 2009 & 255 & 0.5 & & 29 & 42 & 171 & 17 \\
\hline \multicolumn{8}{|c|}{ Reviews and meta-analyses: } \\
\hline Hamani et al. 2005 & 471 & 5 & $58-42$ & $56-49$ & & & \\
\hline $\begin{array}{l}\text { Kleiner-Fisman } \\
\text { et al. } 2006\end{array}$ & 921 & $>0.5$ & 50 & 52 & 68.2 & & 34.5 \\
\hline
\end{tabular}

Table 2. Complication after STN-/GPi-DBS related to surgery and hardware.

\begin{tabular}{|c|c|c|c|c|c|}
\hline & $\begin{array}{l}\text { Number of } \\
\text { patients } \\
\text { (leads) }\end{array}$ & $\begin{array}{l}\text { Follow-up } \\
\text { (months) }\end{array}$ & $\begin{array}{l}\text { Haemorrhage } \\
(\%)\end{array}$ & $\begin{array}{l}\text { Infection/ } \\
\text { erosion } \\
(\%)\end{array}$ & $\begin{array}{l}\text { Hardware } \\
\text { complications } \\
(\%)\end{array}$ \\
\hline \multicolumn{6}{|l|}{ Original studies: } \\
\hline Binder et al. 2003 & 357 leads & 60 & 3.1 & & \\
\hline Temel et al. 2004 & $108(178)$ & $42.6 \pm 22.5$ & & 3.8 & \\
\hline Blomstedt and Hariz, 2005 & $119(161)$ & mean 40 & & 3 & 17.3 \\
\hline Deuschl et al.2006 & $78(156)$ & 6 & 1.9 & 3.8 & 1.3 \\
\hline Goodman et al. 2006 & $100(181)$ & mean 4 & 2 & 4.7 & 11.5 \\
\hline Voges et al. 2006 & 262 (352) & $36.3 \pm 20.8$ & 0.2 & 5.7 & 13.9 \\
\hline Seijo et al.2007 & $130(252)$ & 37 & 6.92 & & 3.84 \\
\hline Kenney et al. 2007 & 319 (507) & 10 & 1.5 & 4.4 & 4 \\
\hline Tir et al. 2007 & $103(206)$ & 1 & 5.8 & 6.8 & 3.9 \\
\hline Sillay et al. 2008 & 420 (759) & 6 & & & 4.5 \\
\hline Weaver et al. 2009 & $121(242)$ & 6 & 0.8 & 9.9 & 6.6 \\
\hline \multicolumn{6}{|l|}{ Reviews and meta-analyses: } \\
\hline Hamani et al. 2005 & 471 & & 2 & & 9 \\
\hline Hamani and Lozano, 2006 & 922 & & 2.8 & 6.1 & 11.4 \\
\hline Kleiner-Fisman et al. 2006 & 921 & & 3.9 & 3.6 & 4.5 \\
\hline Videnovic and Metman 2008 & 1154 (2205) & & 3.8 & 2.9 & 5 \\
\hline
\end{tabular}

[Alegret et al. 2001; Dujardin et al. 2001; Trepanier et al. 2000]. Recently, it was shown that, while there is a selective decrease in frontal cognitive functions, in particular executive functions, DBS of the STN does not reduce overall cognition [Witt et al. 2008; Smeding et al. 2006]. Moreover, modulation of cognitive circuits using STN-DBS has been shown to be frequency dependent: high-frequency DBS leads to a reduction of verbal fluency, while low-frequency DBS at $10 \mathrm{~Hz}$ results in an improvement of verbal fluency [Parsons et al. 2006; Wojtecki et al. 2006].

In the postoperative period transient depressive or mania-like symptoms are frequently found and should be carefully monitored and may sometimes require symptomatic treatment. An overly rapid postoperative withdrawal of dopaminergic medication should be avoided in order not to induce apathy [Funkiewitz et al. 2004; 
Volkmann et al. 2001]. Furthermore STN-DBS might lead to increased emotional lability [Smeding et al. 2006]. Most neuropsychiatric symptoms seem to be transient and, in addition to depression, include hypomania, impulse control disorders, hypersexuality, or apathy and might need an adaptation of stimulation parameters and/or dopaminergic medication [Deuschl et al. 2006; Funkiewitz et al. 2004; Krack et al. 2003; Houeto et al. 2002]. Another more serious concern is a higher than expected occurrence of attempted and completed suicide following DBS. Retrospective analysis revealed completed suicide of $0.45-1 \%$ and attempted suicide of $0.9-2 \%$ following STNDBS, clear motor improvements notwithstanding [Soulas et al. 2008; Voon et al. 2008]. Postoperative suicide attempts were associated with being single, a history of impulse-control disorder or compulsive medication use and postoperative depression or apathy. This increased risk of suicide makes a careful psychiatric preoperative screening and postoperative follow-up very important.

It still is a matter of debate whether the occurrence of psychiatric complications might be target-point dependent. While psychiatric complications are previously described to be less frequent and less severe in GPi-DBS than STN-DBS [Videnovic and Metman, 2008; Rodriguez-Oroz et al. 2005], a recent prospective, randomized study comparing unilateral STN- and GPi-DBS found no significant differences regarding effects on mood and cognition [Okun et al. 2009].

Stimulation induced side effects occur if electrode placement is suboptimal and neighboring structures and fibers are co-stimulated. However, they might also occur as a result of current flow to neighboring structures after increasing the stimulation parameters. Depending on anatomical location, typical side effects include dytharthophonia or hypophonia, tetanic muscle contractions, paresthesias, oculomotor dysfunction, visual phosphenes, nausea, dizziness, dystonia, dyskinesia, or even a worsening of bradykinesia [Deuschl et al. 2006; Guehl et al. 2006; Volkmann et al. 2006; Krack et al. 2002]. Weight gain is also common after STNDBS and might be the consequence of a significant reduction of dyskinesias by DBS [Videnovic and Metman, 2008; Macia et al. 2004]. Adverse mood effects occurred more ventrally in both STN- and GPi-DBS which might be caused by stimulation of nonmotor associative or limbic circuits within the nucleus [Okun et al. 2009]. Single cases of pathological crying and mirthful laughter induced by STN-DBS have also been reported indicating a potential involvement of ponto-cerebellar or limbic pathways of the basal ganglia-cortical circuits for the psychomotor regulation [Wojtecki et al. 2007; Okun et al. 2003; Krack et al. 2001].

Despite the clear improvement of motor function, activity of daily living and quality of life, STNDBS often fails to result in a successful social re-adjustment in the patient's personal, family or professional life [Schüpbach et al. 2006]. Therefore, careful preoperative psychosocial preparation and postoperative psychosocial care are increasingly being recognized as essential parts of patient management [Schüpbach et al. 2006].

\section{Mechanism of action of DBS}

Current hypotheses on the action mechanism of DBS include depolarization blockade [Beurrier et al. 2001], synaptic inhibition [Dostrovsky et al. 2000], synaptic depression [Urbano et al. 2002], stimulation-induced disruption of pathological network activity [Montgomery and Baker, 2000], and stimulation of afferent axons projecting to the STN [Gradinaru et al. 2009]. Depolarization blockade and synaptic inhibition are likely to explain the similarity between the therapeutic benefit of DBS and lesional surgery. Recordings of decreased somatic activation in the stimulated nucleus favor these hypotheses [Dostrovsky et al. 2000; Benazzouz et al. 1995]. However, the increased output of projection neurons does not seem to be mediated by these phenomena [McIntyre et al. 2004a, 2004b; Hashimoto et al. 2003]. Another and currently favored hypothesis is that DBS overrides abnormal spike train patterns by an unphysiological, high-frequency pattern, and thereby masks pathological signals, which cause dysfunction of the remaining elements of the basal ganglia-thalamo-cortical and brainstem motor loop [Garcia et al. 2005]. The exact nature of the abnormal signals and the interaction between stimulation-induced neuronal responses and intrinsic brain activity remains elusive, but abnormalities of the firing rate and pattern of basal-ganglia neurons, changes in oscillatory activity and excessive synchronization at multiple levels of the motor loop have been proposed as pathophysiological correlates of motor symptoms in PD [Brown and Eusebio, 2008; Montgomery and Gale, 2008; Hammond et al. 2007; 
Schnitzler and Gross 2005; Hutchison et al. 2004; Bergman and Deuschl, 2002].

\section{Outlook/Perspectives}

In PD, DBS is currently primarily used to treat severe motor fluctuations or tremor in advanced stages. At that stage, most patients not only show severe impairment in mobility and quality of life but have already experienced psychosocial decline. Once deprived, restoration of mobility does not always result in a return of independency [Schüpbach et al. 2006]. Therefore DBS may be considered as a treatment to be used in earlier stages to protect patients from social isolation. There is evidence that the outcome of motor functions is better and the complication rate is lower when DBS is performed earlier in younger patients [Schüpbach et al. 2007]. A larger clinical trial is required to address the question whether, compared with best medical treatment, surgery could be advantageously performed at an earlier stage of the disease to improve quality of life and help maintain independency for a longer period of time.

\section{Conflict of interest statement}

L.W., M.S. and A.S. have occasionally received honoraria from Medtronic for lecturing at conferences or consulting work.

\section{References}

Ahlskog, J.E. and Muenter, M.D. (2001) Frequency of levodopa-related dyskinesias and motor fluctuations as estimated from the cumulative literature. Mov Disord 16: 448-458.

Alegret, M., Junqué, C., Valldeoriola, F., Vendrell, P., Pilleri, M., Rumià, J. et al. (2001) Effects of bilateral subthalamic stimulation on cognitive function in Parkinson disease. Arch Neurol 58: 1223-1227.

Andrade-Souza, Y.M., Schwalb, J.M., Hamani, C., Hoque, T., Saint-Cyr, J. and Lozano, A.M. (2005) Comparison of 2-dimensional magnetic resonance imaging and 3-planar reconstruction methods for targeting the subthalamic nucleus in Parkinson disease. Surg Neurol 63: 357-362.

Benabid, A.L., Pollak, P., Louveau, A., Henry, S. and de Rougemont, J. (1987) Combined (thalamotomy and stimulation) stereotactic surgery of the VIM thalamic nucleus for bilateral Parkinson disease. Appl Neurophysiol 50: 344-346.

Benabid, A.L., Pollak, P., Gao, D., Hoffmann, D., Limousin, P., Gay, E. et al. (1996) Chronic electrical stimulation of the ventral intermedius nucleus of the thalamus as a treatment of movement disorders.

f Neurosurg 84: 203-214.
Benabid, A.L., Benazzous, A. and Pollak, P. (2002) Mechanisms of deep brain stimulation. Mov Disord 17: S73-S74.

Bennazouz, A., Piallat, B., Pollak, P. and Benabid, A.L. (1995) Responses to substantia nigra pars reticulata and globus pallidus complex to high-frequency stimulation of the subthalamic nucleus in rats: electrophysiological data. Neurosci Lett 189: $77-80$.

Bergman, H. and Deuschl, G. (2002) Pathophysiology of Parkinson's disease: from clinical neurology to basic neuroscience and back. Mov Disord 17: S28-S40.

Beurrier, C., Bioulac, B., Audin, J. and Hammond, C. (2001) High frequency stimulation produces a transient blockade of voltage-gated currents in subthalamic neurons. F Neurophysiol 85: 1351-1356.

Binder, D.K., Rau, G. and Starr, P.A. (2003)

Hemorrhagic complications of microelectrode-guided deep brain stimulation. Stereotact Funct Neurosurg 80: $28-31$.

Blomstedt, P. and Hariz, M.I. (2005) Hardwarerelated complications of deep brain stimulation: a ten year experience. Acta Neurochir (Wien) 147: $1061-1064$.

Brown, P. and Eusebio, A. (2008) Paradoxes of functional neurosurgery: clues from basal ganglia recordings. Mov Disord 23: 12-20.

Burbaud, P., Vital, A., Rougier, A., Bouillot, S., Guehl, D., Cuny, E. et al. (2002) Minimal tissue damage after stimulation of the motor thalamus in a case of chorea-acanthocytosis. Neurology 59: 1982-1984.

Burchiel, K.J., Anderson, V.C., Favre, J. and Hammerstad, J.P. (1999) Comparison of pallidal and subthalamic nucleus deep brain stimulation for advanced Parkinson's disease: results of a randomized. blinded pilot study. I Neurosurg 45: 1375-1382.

Charles, P.D., Van Blercom, N., Krack, P., Lee, S.L., Xie, J., Besson, G. et al. (2002) Predictors of effective bilateral subthalamic nucleus stimulation for PD. Neurology 59: 932-934.

Deuschl, G., Fogel, W., Hahne, M., Kupsch, A., Muller, D., Oechsner, M. et al. (2002) Deep-brain stimulation for Parkinson's disease. 7 Neurol 249: 36-39.

Deuschl, G., Schade-Brittinger, C., Krack, P., Volkmann, J., Schafer, H., Botzel, K. et al. (2006) A randomized trial of deep-brain stimulation for Parkinson's disease. N Engl f Med 355: 896-908.

Dostrovsky, J.O., Levy, R., Wu, J.P., Hutchison, W.D., Tasker, R.R. and Lozano, A.M. (2000) Microstimulation-induced inhibition of neuronal firing in human globus pallidus. $\mathcal{F}$ Neurophysiol 84: 570-574.

Dujardin, K., Defebvre, L., Krystkowiak, P., Blond, S. and Destée, A. (2001) Influence of chronic bilateral 
stimulation of the subthalamic nucleus on cognitive function in Parkinson's disease. F Neurol 248: 603-611.

Esselink, R.A.J., de Bie, R.M.A., de Haan, R.J., Lenders, M.W.P.M., Nijssen, P.C.G., Staal, M.J. et al. (2004) Unilateral pallidotomy versus bilateral subthalamic nucleus stimulation in PD. Neurology 62: 201-207.

Funkiewiez, A., Ardouin, C., Krack, P., Fraix, V., Van Blercom, N., Xie, J. et al. (2003) Acute psychotropic effects of bilateral subthalamic nucleus stimulation and levodopa in Parkinson's disease. Mov Disord 18: 524-530.

Fraix, V., Houeto, J.L., Lagrange, C., Le Pen, C., Krystkowiak, P., Guehl, D. et al. (2006) Clinical and economic results of bilateral subthalamic nucleus stimulation in Parkinson's disease. $\mathcal{F}$ Neurol Neurosurg Psychiatry 77: 443-449.

Garcia, L., D’Alessandro, G., Bioulac, B. and Hammond, C. (2005) High-frequency stimulation in Parkinson's disease: more or less? Trends Neurosci 28: 209-216.

Goetz, C.G., Poewe, W., Rascol, O. and Sampaio, C. (2005) Evidence-based medical review update: pharmacological and surgical treatments of Parkinson's disease: 2001 to 2004. Mov Disord 20: 523-539.

Goodman, R.R., Kim, B., McClelland 3rd, S., Senatus, P.B., Winfield, L.M. and Pullman, S.L. (2006) Operative techniques and morbidity with subthalamic nucleus deep brain stimulation in 100 consecutive patients with advanced Parkinson's disease. F Neurol Neurosurg Psychiatry 77: 12-17.

Gradinaru, V., Mogri, M., Thompson, K.R., Henderson, J.M. and Deisseroth, K. (2009) Optical destruction of parkinsonian neural circuitry. Science 324: 354-359.

Guehl, D., Cuny, E., Benazzouz, A., Rougier, A., Tison, F., Machado, S. et al. (2006) Side-effects of subthalamic stimulation in Parkinson's disease: clinical evolution and predictive factors. Eur $\mathcal{F}$ Neurol 13: 963-971.

Haberler, C., Alesch, F., Mazal, P.R., Pilz, P., Jellinger, K. and Pinter, M.M. (2000) No tissue damage by chronic deep brain stimulation in Parkinson's disease. Ann Neurol 48: 372-376.

Hamani, C., Richter, E.O., Andrade-Souza, Y., Hutchison, W., Saint-Cyr, J.A. and Lozano, A.M. (2005) Correspondence of microelectrode mapping with magnetic resonance imaging for subthalamic nucleus procedures. Surg Neurol 63: 249-253.

Hamani, C., Richter, E., Schwalb, J.M. and Lozano, A.M. (2005) Bilateral subthalamic nucleus stimulation for Parkinson's disease: a systematic review of the clinical literature. Neurourgery 56: 1313-1321.

Hamani, C. and Lozano, A.M. (2006) Hardwarerelated complications of deep brain stimulation: a review of the published literature. Stereotact Funct Neurosurg 84: 248-251.

Hammond, C., Bergman, H. and Brown, P. (2007) Pathological synchronization in Parkinson's disease: networks, models and treatments. Trends Neurosci 30: 357-364.

Hariz, M.I. (2002) Safety and risk of microelectrode recording in surgery for movement disorders. Stereotact Funct Neurosurg 78: 146-157.

Hariz, M.I., Krack, P., Alesch, F., Augustinsson, L.E., Bosch, A., Ekberg, R. et al. (2008) Multicentre European study of thalamic stimulation for parkinsonian tremor: a 6 year follow-up. $\mathcal{F}$ Neurol Neurosurg Psychiatry 79: 694-699.

Hariz, M.I., Rehncrona, S., Quinn, N.P., Speelman, J.D., Wensing, C. and the Multicentre Advanced Parkinson's Disease Deep Brain Stimulation Group. (2008) Multicenter Study on Deep Brain Stimulation in Parkinson's Disease: An Independent Assessment of Reported Adverse Events at 4 Years. Mov Disord 23: 416-421.

Hashimoto, T., Elder, C.M., Okun, M.S., Patrick, S.K. and Vitek, J.L. (2003) Stimulation of the subthalamic nucleus changes the firing pattern of pallidal neurons. F Neurosci Methods 23: 1916-1923.

Herzog, J., Fietzek, U., Hamel, W., Morsnowski, A., Steigerwald, F., Schrader, B. et al. (2004) Most effective stimulation site in subthalamic deep brain stimulation for Parkinson's disease. Mov Disord 19: 1050-1054.

Herzog, J., Weiss, P.H., Assmus, A., Wefer, B., Seif, C., Braun, P.M. et al. (2006) Subthalamic stimulation modulates cortical control of urinary bladder in Parkinson's disease. Brain 129: 3366-3375.

Hilker, R., Portman, A.T., Voges, J., Staal, M.J., Burghaus, L., van Laar, T. et al. (2005) Disease progression continues in patients with advanced Parkinson's disease and effective subthalamic nucleus stimulation. I Neurol Neurosurg Psychiatry 76: 1217-1221.

Hilker, R., Benecke, R., Deuschl, G., Fogel, W., Kupsch, A., Schrader, C. et al. (2009) Deep brain stimulation for Parkinson's disease: Consensus recommendations of the German Deep Brain Stimulation Association. Nervenarzt Epub ahead of print.

Houeto, J.L., Mesnage, V., Mallet, L., Pillon, B., Gargiulo, M., Teyenas du Moncel, S. et al. (2002) Behavioural disorders, Parkinson's disease and subthalamic stimulation. FNNP 72: 701-707.

Hughes, A.J., Ben-Shlomo, Y., Daniel, S.E. and Lees, A.J. (1992) What features improve the accuracy of clinical diagnosis in Parkinson's disease: a clinicopathologic study. Neurology 57: S34-38.

Hutchison, W.D., Dostrowsky, J.O., Walters, J.R., Courtemanche, R., Boraud, T., Goldberg, J. et al. (2004) Neuronal oscillations in the basal ganglia 
and movement disorders: evidence from whole animal and human recordings. $\mathcal{F}$ Neurosci 24: 9240-9243.

Kenney, C., Simpson, R., Hunter, C., Ondo, W., Almaguer, M. and Davidson, A. (2007) Short-term and long-term safety of deep brain stimulation in the treatment of movement disorders. $\mathcal{F}$ Neurosurg 106: 621-625.

Kleiner-Fisman, G., Fisman, D.N., Sime, E., Saint-Cyr, J.A., Lozano, A.M. and Lang, A.E. (2003) Long term follow up of bilateral deep brain stimulation of the subthalamic nucleus in patients with advanced Parkinson's disease. $\mathcal{F}$ Neurosurg 99: 489-495.

Kleiner-Fisman, G., Herzog, J., Fisman, D.N., Tamma, F., Lyons, K.E., Pahwa, R. et al. (2006) Subthalamic nucleus deep brain stimulation: summary and meta-analysis of outcomes. Mov Disord 21: S290-S304.

Krack, P., Pollak, P., Limousin, P., Benazzouz, A. and Benabid, A.L. (1997) Stimulation of subthalamic nucleus alleviates tremor in Parkinson's disease. Lancet 350: 1676

Krack, P., Pollak, P., Limousin, P., Hoffmann, D., Xie, J., Benazzouz, A. et al. (1998) Subthalamic nucleus or internal pallidal stimulation in young onset Parkinson's disease. Brain 121: 451-457.

Krack, P., Pollak, P., Limousin, P., Benazzouz, A., Deuschl, G. and Benabid, A.L. (1999) From offperiod dystonia to peak-dose chorea. The clinical spectrum of varying subthalamic nucleus activity. Brain 122: 1133-1146.

Krack, P., Kumar, R., Ardouin, C., Dowsey, P.L., McVicker, J.M., Benabid, A.L. et al. (2001) Mirthful laughter induced by subthalamic nucleus stimulation. Mov Disord 16: 867-875.

Krack, P., Fraix, V., Mendes, A., Benabid, A.L. and Pollak, P. (2002) Postoperative management of subthalamic nucleus stimulation for Parkinson's disease. Mov Disord 17: S188-S197.

Krack, P., Batir, A., Van Blercom, N., Chabardes, S., Fraix, V., Ardouin, C. et al. (2003) Five-year follow-up of bilateral stimulation of the subthalamic nucleus in advanced Parkinson's disease. N Engl F Med 349: 1925-1934.

Kumar, R., Lozano, A.M., Kim, Y.J., Hutchison, W.D., Sime, E., Halket, E. et al. (1998) Double-blind evaluation of subthalamic nucleus deep brain stimulation in advanced Parkinson's disease. Neurology 51: 850-855.

Kumar, R., Lozano, A.M., Sime, E., Halket, E. and Lang, A.E. (1999) Comparative effects of unilateral and bilateral subthalamic nucleus deep brain stimulation. Neurology 53: 561-566.

Kuncel, A.M. and Grill, W.M. (2004) Selection of stimulus parameters for deep brain stimulation. Clinical Neurophysiology 115: 2431-2441.
Lang, A.E., Houeto, J.L., Krack, P., Kubu, C., Lyons, K.E., Moro, E. et al. (2006) Deep brain stimulation: preoperative issues. Mov Disord 21: S171-S196.

Langston, J.W., Widner, H., Goetz, C.G., Brooks, D., Fahn, S., Freeman, T. et al. (1992) Core Assessment Program for Intracerebral Transplantation. Mov Disord 7: $2-13$

LeWitt, P.A. (2008) Levodopa for the treatment of Parkinson's disease. N Engl f Med 359: 2468-2476.

Limousin, P., Krack, P., Pollak, P., Benazzouz, A., Ardouin, C., Hoffmann, D. et al. (1998) Electrical stimulation of the subthalamic nucleus in advanced Parkinson's disease. N Engl f Med 339: 1105-1011.

Limousin, P., Speelman, J.D., Gielen, F. and Janssens, M. (1999) Multicentre European study of thalamic stimulation in parkinsonian and essential tremor. $\mathcal{F}$ Neurol Neurosurg 66: 289-296.

Lozano, A.M., Hutchison, W.D., Tasker, R.R., Lang, A.E., Junn, F. and Dostrovsky, J.O. (1998)

Microelectrode recordings define the ventral posteromedial pallidotomy target. Stereotact Funct Neurosurg 71: 153-163.

Lyons, K.E., Wilkinson, S.B., Overman, J. and Pahwa, R. (2004) Surgical and hardware complications of subthalamic stimulation: a series of 160 procedures. Neurology 63: 612-616.

Macia, F., Perlemoine, C., Coman, I., Guehl, D., Burbaud, P. and Cuny, E. (2004) Parkinson's disease patients with bilateral subthalamic deep brain stimulation gain weight. Mov Disord 19: 206-212.

McIntyre, C.C., Savasta, M., Kerkerian-Le Goff, L. and Vitek, J.L. (2004a) Uncovering the mechanism(s) of action of deep brain stimulation: activation, inhibition, or both. Clin Neurophysiol 115: 1239-1248.

McIntyre, C.C., Grill, W.M., Shermann, D.L. and Thakor, N.V. (2004b) Cellular effects of deep brain stimulation: model-based analysis of activation and inhibition. F Neurophysiol 91: 1457-1469.

Montgomery Jr, E.B. and Baker, K.B. (2000) Mechanisms of deep brain stimulation and future technical developments. Neurol Res 22: 259-266.

Montgomery Jr, E.B. and Gale, J.T. (2008) Mechanisms of action of deep brain stimulation. Neurosci Behav Rev 32: 388-407.

Moro, E., Poon, Y.Y., Lozano, A.M., Saint-Cyr, J.A. and Lang, A.E. (2006) Subthalamic nucleus stimulation: improvements in outcome with reprogramming. Arch Neurol 63: 1266-1272.

Moro, E., Volkmann, J., König, I.R., Winkler, S., Hiller, A. and Hassin-Baer, S. (2008) Bilateral subthalamic stimulation in Parkin and PINK1 parkinsonism. Neurology 70: 1186-1191.

Oh, M.Y., Abosch, A., Kim, S.H., Lang, A.E. and Lozano, A.M. (2002) Long-term hardware-related complications of deep brain stimulation. Neurosurgery 50: $1268-1274$. 
Okun, M.S., Green, J., Saben, R., Gross, R., Foote, K.D. and Vitek, J.L. (2003) Mood changes with deep brain stimulation of STN and GPi: results of a pilot study. 7 Neurol Neurosurg Psychiatry 74: 1584-1586.

Okun, M.S., Fernandez, H.H., Wu, S.S., KirschDarrow, L., Bowers, D., Bova, F. et al. (2009) Cognition and mood in Parkinson's disease in subthalamic nucleus versus globus pallidus interna deep brain stimulation: The COMPARE Trial. Ann Neurol Epub ahead of print.

Olanow, C.W., Watts, R.L. and Koller, W.C. (2001) An algorithm (decision tree) for the management of Parkinson's disease: treatment guidelines. Neurology 56: S1-S88.

Pahwa, R., Wilkinson, S.B., Overman, J. and Lyons, K.E. (2003) Bilateral subthalamic stimulation in patients with Parkinson disease: long-term follow up. f Neurosurg 99: 71-77.

Pahwa, R., Factor, S.A., Lyons, K.E., Ondo, W.G., Gronseth, G., Bronte-Stewart, H. et al. (2006) Practice Parameter: Treatment of Parkinson disease with motor fluctuations and dyskinesia (an evidencebased review): Report of the Quality Standards Subcommittee of the American Academy of Neurology. Neurology 66: 983-995.

Palur, R.S., Berk, C., Schulzer, M. and Honey, C.R. (2002) A metaanalysis comparing the results of pallidotomy performed using microelectrode recording or macroelectrode stimulation. F Neurosurg 96: 1058-1062.

Parsons, T.D., Rogers, S.A., Braaten, A.J., Woods, S.P. and Tröster, A.I. (2006) Cognitive sequelae of subthalamic nucleus deep brain stimulation in Parkinson's disease: a meta-analysis. Lancet Neurol 5: 578-588.

Pilitsis, J.G., Chu, Y., Kordower, J., Bergen, D.C., Cochran, E.J. and Bakay, R.A. (2008) Postmortem study of deep brain stimulation of the anterior thalamus: case report. Neurosurgery 62: E530-E532.

Plaha, P., Ben-Shlomo, Y., Patel, N.K. and Gill, S.S. (2006) Stimulation of the caudal zona incerta is superior to stimulation of the subthalamic nucleus in improving contralateral parkinsonism. Brain 29: $1732-1747$.

Rascol, O., Brooks, D.J., Korczyn, A.D., De Deyn, P.P., Clarke, C.E. and Lang, A.E. (2000) A five-year study of dyskinesia in patients with early Parkinson's disease who were treated with ropinirole or levodopa. 056 Study Group. N Engl F Med 342: 1484-1491.

Rodriguez-Oroz, M.C., Obeso, J.A., Lang, A., Houeto, J.L., Pollak, P. and Rehncrona, S. (2005) Bilateral deep brain stimulation in Parkinson's disease: a multicentre study with 4 years follow-up. Brain 128: 2240-2249.

Schaltenbrand, G. and Bailey, P.(1959)

Introduction to stereotaxis with an atlas of the human brain, Thieme: Stuttgart.
Schaltenbrand, G. and Wahren, W.(1977) Atlas for stereotaxy of the human brain, Thieme: Stuttgart.

Schneider, F., Habel, U., Volkmann, J., Regel, S., Kornischka, J. and Sturm, V. (2003) Deep brain stimulation of the subthalamic nucleus enhances emotional processing in Parkinson disease. Arch Gen Psychiatry 60: 296-302.

Schnitzler, A. and Gross, J. (2005) Normal and pathological oscillatory communication in the brain. Nat Rev Neurosci 6: 285-296.

Schuurman, P.R., de Bie, R.M., Majoie, C.B., Speelman, J.D., Bosch, D.A. et al. (1999) A prospective comparison between three-dimensional magnetic resonance imaging and ventriculography for target-coordinate determination in frame-based functional stereotactic neurosurgery. $\mathcal{F}$ Neurosurg 91: 911-9114.

Schuurmann, P.R., Bosch, D.A., Bossuyt, P.M.M., Bonsel, G.J., van Someren, E.J.W. and De Bie, R.M.A. (2000) A comparison of continuous thalamic stimulation and thalamotomy for suppression of severe tremor. N Engl f Med 342: 461-468.

Schüpbach, M., Gargiulo, M., Welter, M.L., Mallet, L., Béhar, B., Houeto, J.L. et al. (2006) Neurosurgery in Parkinson disease A distressed mind in a repaired body? Neurology 66: 1811-1816.

Schüpbach, W.M., Maltête, D., Houeto, J.L., du Montcel, S.T., Mallet, L., Welter, M.L. et al. (2007) Neurosurgery at an earlier stage of Parkinson disease: a randomized, controlled trial. Neurology 68: 267-271.

Seijo, F.J., Alvarez-Vega, M.A., Gutierrez, J.C., Fdez-Glez, F., Lozano, B. et al. (2007) Complications in subthalamic nucleus stimulation surgery for treatment of Parkinson's disease. Review of 272 procedures. Acta Neurochir (Wien) 149: 867-875.

Sillay, K.A., Larson, P.S. and Starr, P.A. (2008) Deep brain stimulator hardware-related infections: incidence and management in a large series. Neurosurg 62: 360-366.

Smeding, H.M.M., Speelman, J.D., Koning-Haanstra, M., Schuurman, P.R., Nijssen, P., van Laar, T. et al. (2006) Neuropsychological effects of bilateral STN stimulation in Parkinson disease. A Controlled Study Neurology 66: 1830-1836.

Soulas, T., Gurruchaga, J.M., Palfi, S., Cesaro, P., Nguyen, J.P. and Fénelon, G. (2008) Attempted and completed suicides after subthalamic nucleus stimulation for Parkinson's disease. 7 Neurol Neurosurg Psychiatry 79: 952-954.

Stefani, A., Lozano, A.M., Peppe, A., Stanzione, P., Galati, S., Tropepi, D. et al. (2007) Bilateral deep brain stimulation of the pedunculopontine and subthalamic nuclei in severe Parkinson's disease. Brain 130: 1596-1607.

Starr, P.A., Vitek, J.L., DeLong, M. and Bakay, R.A. (1999) Magnetic resonance imaging based stereotactic 
localization of the globus pallidus and subthalamic nucleus. Neurosurgery 44: 303-314.

Talairach, J., David, M. and Tournoux, P.(1957) Atlas d'anatomie stéréotaxique des nozaux gris centraux, Vol 1, Masson: Paris.

Temel, Y., Ackermans, L., Celik, H., Spincemaille, G.H., van der Linden, C., Walenkamp, G.H. et al. (2004) Management of hardware infections following deep brain stimulation. Acta Neurochir (Wien) 146: 355-361.

Tir, M., Devos, D., Blond, S., Touzet, G., Reyns, N., Duhamel, A. et al. (2007) Exhaustive, one-year followup of subthalamic nucleus deep brain stimulation in a large, single-center cohort of parkinsonian patients. Neurosurgery 61: 297-304.

Temel, Y., Visser-Vandervalle, V., Kaplan, S., Kozan, R., Daemen, M.A., Blokland., A. et al. (2006) Protection of nigral cell death by bilateral subthalamic nucleus stimulation. Brain Res 1120: 100-105.

The Deep Brain Stimulation for Parkinson's disease study group. (2001) Deep brain stimulation of the subthalamic nucleus or the pars interna of the globus pallidus in Parkinson's disease. $N$ Engl f Med 345: 956-963.

Trépanier, L.L., Kumar, R., Lozano, A.M., Lang, A.E. and Saint-Cyr, J.A. (2000) Neuropsychological outcome of GPi pallidotomy and GPi or STN deep brain stimulation in Parkinson's disease. Brain Cogn 42: 324-347.

Urbano, F.J., Leznik, E. and Llinas, R.R. (2002) Cortical activation patterns evoked by afferent axons stimuli at different frequencies: an in vivo voltagesensitive dye imaging study. Thalamus Rel Syst 1: 371-378.

Vayssiere, N., Hemm, S., Cif, L., Picot, M.C., Diakonova, N., El Fertit, H. et al. (2002)

Comparison of atlas- and magnetic resonance imaging-based stereotactic targeting of the globus pallidus internus in the performance of deep brain stimulation for treatment of dystonia. $\mathcal{F}$ Neurosurg 96: 673-679.

Videnovic, A. and Metman, L.V. (2008) Deep brain stimulation for Parkinson's disease: prevalence of adverse events and need for standardized reporting. Mov Disord 23: 343-349.

Visser-Vandewalle, V., van der Linden, C., Temel, Y., Celik, H., Ackermans, L. and Spincemaille, G. (2005) Long term effects of bilateral subthalamic nucleus stimulation in advanced Parkinson disease: a four year follow-up study. Parkinsonism Relat Disord

11: $157-165$.

Voges, J., Volkmann, J., Allert, N., Lehrke, R., Koulousakis, A., Freund, H.J. et al. (2002) Bilateral high-frequency stimulation in the subthalamic nucleus for the treatment of Parkinson disease: correlation of therapeutic effect with anatomical electrode position. f Neurosurg 96: 269-279.
Voges, J., Waerzeggers, Y., Maarouf, M., Lehrke, R., Koulousakis, A., Lenartz, D. et al. (2006) Deep-brain stimulation: long-term analysis of complications caused by hardware and surgery-experiences from a single centre. F Neurol Neurosurg Psychiatry 77: 772-868.

Voges, J., Hilker, R., Bötzel, K., Kiening, K.L., Kloss, M., Kupsch, A. et al. (2007) Thirty days complication rate following surgery performed for deep-brainstimulation. Mov Disord 22: 1486-1489.

Volkmann, J., Sturm, V., Weiss, P., Kappler, J., Voges, J., Koulousakis, A. et al. (1998) Bilateral high-frequency stimulation of the internal globus pallidus in advanced Parkinson's disease. Ann Neurol 44: 953-961.

Volkmann, J., Fogel, W. and Krack, P. (2000) Postoperatives neurologisches Management bei Stimulation des Nucleus subthalamicus. Aktuelle Neurologie 27: 23-39.

Volkmann, J., Allert, N., Voges, J., Weiss, P.H., Freund, H.J. and Sturm, V. (2001) Safety and efficacy of pallidal or subthalamic nucleus stimulation in advanced PD. Neurology 56: 548-551.

Volkmann, J., Allert, N., Voges, J., Sturm, V., Schnitzler, A. and Freund, H.J. (2004) Long-term results of bilateral pallidal stimulation in Parkinson's disease. Ann Neurol 55: 871-875.

Volkmann, J., Moro, E. and Pahwa, R. (2006) Basic algorithms for the programming of deep brain stimulation in Parkinson's disease. Mov Disord 21: S284-S289.

Voon, V., Krack, P., Lang, A.E., Lozano, A.M., Dujardin, K., Schüpbach, M. et al. (2008) A multicentre study on suicide outcomes following subthalamic stimulation for Parkinson's disease. Brain 131: 2720-2728.

Wallace, B.A., Ashkan, K., Heise, C.E., Foote, K.D., Torres, N., Mitrofanis, J. et al. (2007) Survival of midbrain dopaminergic cells after lesion or deep brain stimulation of the subthalamic nucleus in MPTPtreated monkeys. Brain 130: 2129-2145.

Weaver, F., Follett, K., Hur, K., Ippolito, D. and Stern, M. (2005) Deep brain stimulation in Parkinson disease: a metaanalysis of patient outcomes. F Neurosurg 103: 956-967.

Weaver, F.M., Follett, K., Stern, M., Hur, K., Harris, C., Marks Jr, W.J. et al. (2009) Bilateral deep brain stimulation vs best medical therapy for patients with advanced Parkinson disease: arandomized controlled trial. FAMA 301: 63-73.

Welter, M.L., Houeto, J.L., Tezenas du Montcel, S., Mesnage, V., Bonnet, A.M., Pillon, B. et al. (2002) Clinical predictive factors of subthalamic stimulation in Parkinson's disease. Brain 125: 575-583.

Witt, K., Daniels, C., Reiff, J., Krack, P., Volkmann, J., Pinsker, M.O. et al. (2008) Neuropsychological and psychiatric changes after deep brain stimulation for 
Parkinson's disease: a randomised, multicentre study. Lancet Neurol 7: 605-614.

Wojtecki, L., Timmermann, L., Jorgens, S., Sudmeyer, M., Maarouf, M. and Treuer, H. (2006)

Frequency-dependent reciprocal modulation of verbal fluency and motor functions in subthalamic deep brain stimulation. Arch Neurol 63: 1273-1276.

Wojtecki, L., Nickel, J., Timmermann, L., Maarouf, M., Südmeyer, M., Schneider, F. et al. (2007) Pathological crying induced by deep brain stimulation. Mov Disord 22: 1314-1316.
Visit SAGE journals online http://tan.sagepub.com

(SSAGEJOURNALS 